The European Journal of Finance 10, 510-525 (December 2004)

\title{
The statistical evolution of prices on the Istanbul Stock Exchange
}

\author{
ATTILA ODABAŞI ${ }^{1}$, CELAL AKSU ${ }^{2 *}$ and VEDAT AKGIRAY ${ }^{1}$ \\ ${ }^{1}$ Faculty of Economics \& Administrative Sciences, Boğaziçi University, \\ Istanbul, Turkey \\ ${ }^{2}$ School of Management, University of Texas at Dallas, USA
}

This study documents the statistical properties of the stock returns on the Istanbul Stock Exchange (ISE) for the January 1988 to December 1999 period and tries to assess the evolution of the underlying stochastic structure over this time period. It also investigates empirically the relative efficiency of the ISE to test whether the rapid development of this market over the last decade caused it to become a relatively more efficient market. This is accomplished through a number of parametric and non-parametric tests of the random walk hypothesis using daily, weekly and monthly observations of the value-weighted ISE100 index series. The emphasis is more on the evolution of the price process than on static tests of a random walk model as such. The findings indicate that the price mechanism in the ISE has evolved into a more informationally efficient process in little more than a decade of existence.

Keywords: market efficiency, emerging markets, ISE Index returns, unit-root tests, varianceratio tests, non-stationarity

Financial markets in Turkey were strictly regulated until a financial liberalization programme was introduced at the beginning of 1980 . The programme included the liberalization of the foreign exchange regime, deregulation of interest rates, and establishment of financial markets including the Istanbul Stock Exchange (ISE), which became operational later in 1986. Over time, the development of ISE became highly representative of an emerging market with rapid growth in terms of market capitalization, trade volume and number of listed companies as well as the high volatility in returns. In 1986, 80 stocks were listed and the annual volume of trade was $\$ 13$ million. The number of stocks listed on the ISE reached 315 , and the annual volume of trade topped $\$ 181.9$ billion in 2000 , as shown in Panel A of Table 1. Not surprisingly, the market capitalization of ISE grew fast. It increased from $\$ 0.9$ billion at the end of 1986 to $\$ 114$ billion by the end of 1999 , before declining to $\$ 69.5$ billion

\footnotetext{
* Correspondence author: C. Aksu, School of Management, Accounting Department, University of Texas at Dallas, P.O. Box 830688, SM 41, Richardson, Texas 75083-0688, USA. Tel.: +1(972)883-4426; Fax: +1(972)883-6811; E-mail: caksu@utdallas.edu
} 
Table 1. Development of the ISE

Panel A: In numbers

\begin{tabular}{|c|c|c|c|c|c|}
\hline \multirow[b]{3}{*}{ Year } & \multirow{2}{*}{$\begin{array}{l}\text { Number of } \\
\text { companies }\end{array}$} & \multicolumn{2}{|c|}{ Volume of trade } & \multirow{2}{*}{$\begin{array}{l}\text { Total market } \\
\text { capitalization }\end{array}$} & \multirow{2}{*}{$\begin{array}{l}\text { Annual rate } \\
\text { of return }\end{array}$} \\
\hline & & Total & Daily average & & \\
\hline & $\begin{array}{l}\text { End of } \\
\text { year }\end{array}$ & $\begin{array}{l}\text { US\$ } \\
\text { (millions) }\end{array}$ & $\begin{array}{l}\text { US\$ } \\
\text { (millions) }\end{array}$ & $\begin{array}{l}\text { US\$ } \\
\text { (millions) }\end{array}$ & $\%$ Turkish lira \\
\hline 1986 & 80 & 13 & 0.05 & 938 & 71 \\
\hline 1987 & 82 & 118 & 0.47 & 3,125 & 294 \\
\hline 1988 & 79 & 115 & 0.45 & 1,128 & -44 \\
\hline 1989 & 76 & 773 & 3.03 & 6,756 & 493 \\
\hline 1990 & 110 & 5,854 & 23.70 & 18,737 & 47 \\
\hline 1991 & 134 & 8,502 & 34.42 & 15,564 & 34 \\
\hline 1992 & 145 & 8,567 & 34.13 & 9,922 & -8 \\
\hline 1993 & 160 & 21,771 & 88.50 & 37,824 & 417 \\
\hline 1994 & 176 & 23,203 & 91.71 & 21,785 & 32 \\
\hline 1995 & 205 & 52,357 & 208.59 & 20,782 & 47 \\
\hline 1996 & 228 & 37,737 & 152.78 & 30,797 & 144 \\
\hline 1997 & 258 & 58,104 & 230.57 & 61,879 & 254 \\
\hline 1998 & 277 & 70,396 & 283.85 & 33,975 & -25 \\
\hline 1999 & 285 & 84,034 & 356.08 & 114,271 & 485 \\
\hline 2000 & 315 & 181,934 & 739.57 & 69,507 & -38 \\
\hline \multicolumn{6}{|c|}{ Panel B: In events } \\
\hline Period & \multicolumn{5}{|c|}{ Important developments } \\
\hline $1980-1985$ & \multicolumn{5}{|c|}{$\begin{array}{l}\text { Launch of liberalization program; start of primary and secondary markets; adoption } \\
\text { of the New Banks Act; Securities Markets Law }\end{array}$} \\
\hline $1986-1987$ & \multicolumn{5}{|c|}{$\begin{array}{l}\text { First bonds issued by the Treasury; start of the interbank market; Istanbul Stock } \\
\text { Exchange; open market operations by the Central Bank }\end{array}$} \\
\hline $1988-1990$ & \multicolumn{5}{|c|}{$\begin{array}{l}\text { Membership in SWIFT; convertibility of the Lira; lift of restrictions on capital flows: } \\
\text { first ADR issue in the NYSE; ISE Clearing House }\end{array}$} \\
\hline $1991-1992$ & \multicolumn{5}{|c|}{ ISE bond market; repo market; EFT system; Insider Trading Law; ISE joining WFE } \\
\hline $1993-1994$ & \multicolumn{5}{|c|}{$\begin{array}{l}\text { First overseas exchange listing; rights market in the ISE; recognition of the ISE by } \\
\text { the US SEC; full computerized trading in the ISE }\end{array}$} \\
\hline 1995-1996 & \multicolumn{5}{|c|}{$\begin{array}{l}\text { Customs Unions with the EU; regulation of short sales; first insider trading } \\
\text { prosecution; Futures Market in the ISE; ISE joining FEAS }\end{array}$} \\
\hline 1997-1998 & \multicolumn{5}{|c|}{$\begin{array}{l}\text { Various new sub-markets under the ISE; ISE becoming project-leader in } \\
\text { Southeastern European Exhanges; street-name replaced by customer name }\end{array}$} \\
\hline 1999-2000 & \multicolumn{5}{|c|}{ Free float regime; Banking Law based on BIS/Basel criteria } \\
\hline
\end{tabular}

within a year. Thus, using the plain dictionary meaning of the word 'emerge', the ISE has behaved as an 'emerging market'.

The categorization of economies into developed versus emerging economies is a World Bank design. In their concise review of research on emerging markets, Bekaert and Harvey (2002) relate such a categorization to economic and financial 
integration with the world markets. Economic integration requires the elimination of barriers to international trade, and financial integration requires the free flow of capital across borders. Integration as such is typically a slow process requiring a sequence of regulatory and institutional changes in the workings of financial markets. Listed in Panel B of Table 1 are some selected important institutional and regulatory events concerning the Turkish financial markets since 1980. These facts show that Turkey has spent the last two decades taking political and regulatory measures to integrate its markets with the rest of the world, both economically and financially.

Naturally, regulatory reforms cannot guarantee successful and immediate integration. The implementation of the reforms is more indicative of the process of developing into an efficient market. The only objective way of identifying the stage of development is through discovering the empirical properties of the data produced by the market. Summarizing the findings of various studies on emerging markets, Bekaert and Harvey (2002) report that market integration reduces expected returns, decreases volatility, increases correlations with other world markets and causes an increase in capital flows. But the normality of market returns is not obtained even long after integration.

This study is based on the premise that the most informative picture of a market's emergence into a developed market can be obtained through investigating the statistical properties of its price processes over time. The same regulatory or institutional reforms may have very different impacts on different country markets. Each market has its own history and participants with their unique psycophysiological characteristics. All of these are likely to affect the nature and the speed of evolution of price processes.

In general, research on stock returns in emerging markets indicates that these markets are characterized by high volatility and high average returns. In this sense, the Turkish market is highly representative of an emerging market. The statistical properties of stock returns in the ISE continue to be the subject of a growing number of empirical research projects. There is, however, much more to be understood about the Turkish market. Most importantly, an investigation of the evolution of the underlying stochastic structure over time can tell a lot about the present quality of this particular market and the direction in which it is heading. This paper aims at contributing to this issue by investigating the statistical properties of the stock returns in the ISE over the first decade of the exchange.

The informational efficiency of a market cannot be tested by studying only the resulting statistical properties of prices. In theory, market efficiency also depends on the regulatory and institutional environment in which information is generated and used. Owing to a great collection of studies on efficiency (Fama, 1970, 1991; LeRoy, 1973; Lucas, 1978; Grossman and Stiglitz, 1980; Black, 1986, to name a few), the old belief that market efficiency implies a random walk process for prices is now known to be an unrealistic textbook argument. The predictability of prices, at least to 'some' degree and by 'some' number of traders, does not have to imply inefficiency. In fact, price discovery in financial markets requires that traders with a competitive advantage (for example, those with better information and better technology) should be able to get higher returns. However, 'consistent' excess 
returns would seem to pre-require 'consistent' competitive advantage. Otherwise, as the other players begin to learn from the more informed traders, such excess returns may only live for short periods of time. In other words, a trading rule that can generate excess returns for a period of time will have to be replaced with a new rule based on new information and better technology.

Even if there existed one virtual definition of 'absolute market efficiency,' it would be impossible to test it empirically. However, it is still possible and useful to conduct tests of 'relative' efficiency. One such test would compare the relative degrees of efficiency of two separate markets with respect to a given set of information. Similarly, it is useful to investigate the relative efficiency of a given market over time and see if there is a movement towards more relative efficiency as time passes. For example, Lo and MacKinlay (1999) summarize their previous research and report that the 1986-1996 period conforms more closely to a relatively efficient market than the preceding 1962-1985 period in NYSE data. Campbell et al. (1997, pp. 65-67) also present results showing no rejection for the simple random walk hypothesis using a value-weighted portfolio of weekly returns. Most of the earlier studies (Poterba and Summers, 1988; Lo and MacKinlay, 1988; Fama and French, 1988) had rejected the random walk model. As more sophisticated techniques are developed to wipe out arbitrage opportunities, movement towards more relative efficiency is observed over time. This approach would seem to be even more interesting in the case of emerging markets since the stage of development is always a pondered issue for developing economies.

In the finance literature, the terms 'random walk' and 'efficient market' are often inappropriately used to mean the same and, furthermore, each is used to describe a number of different situations. In applied probability, random walk is typically used to mean a strict white noise process, which is basically a process with weakly stationary and independent increments. A special case is obtained if the increments are also identically distributed. If the distribution of the increments is normal, then the celebrated Brownian motion is obtained. The term random walk is also used to mean a process with uncorrelated (that is, linearly independent) increments only, which is known as a white noise process. Unless the increments are normal, whiteness does not imply strict whiteness.

Abundant empirical evidence over decades of research shows that increments of stock prices are neither normal nor identically distributed. (Cowles and Jones, 1937; Fama, 1965; Aldous, 1989; Berlung and Liljeblom, 1990; Chan and Lakonishok, 1992). As a manifestation of the central limit theorem, normality may be obtained as returns are summed over time. However, it is naturally unrealistic to expect returns to remain identically distributed over sufficiently long periods of time. Empirical evidence also shows that time series of stock prices exhibit non-linear dependence and hence the better fit of models such as ARCH and GARCH to price data than the normal distribution (Engle, 1982; Bollerslev, 1986). As a result, a strict white noise is not supported empirically. The relevant empirical question is then whether stock prices form a white noise process. This is also important in practice because it is easier to earn excess returns by exploiting any linear dependence in prices than exploiting complex non-linear structures. In fact, the more sensible tests of relative market efficiency have concentrated on tests of whiteness in prices series. 
The objective of this paper is to test empirically whether the rapid development of the Turkish stock market over the last decade caused this market to become a relatively more efficient market. This is accomplished through a number of parametric and non-parametric tests of the random walk hypothesis over different periods of time. The paper is organized as follows. In the following section the methodology utilized in this paper is explained and the data are described. This is followed by a presentation of the findings, and finally, by conclusions.

\section{DATA AND METHODOLOGY}

The study uses a sample of 2980 daily, 593 weekly and 144 monthly observations of the value-weighted ISE100 index series for the period January 1988 through December 1999. The weekly returns are computed using the closing value for Friday of each week. The monthly returns are computed using the closing value of the last day of each month. Besides the index series, individual stock data are used to construct size-sorted portfolios. Daily and weekly returns are computed for three size-sorted portfolios using the daily individual stock returns. Stocks are assigned to large-size, medium-size, and small-size company portfolios based on the group the beginning-of-year market capitalization belongs to. The portfolios are equal-weighted and have a changing composition.

Throughout the study, rate of return is calculated as the logarithm of successive price relatives: $R_{t}=\ln \left(P_{t} / P_{t-1}\right)$. All calculations are carried out for a variety of time periods: (i) for the full sample period from 1988 to 1999, for two subperiods 1988-94 and 1995-99; (ii) for each and every year; and (iii) for updated periods starting with 1988-99 and ending with 1998-99. The methodology covers a wide range of univariate tests of a white noise process and aims at portraying the evolution of the parameters through time.

\section{RESULTS}

The study of the data starts with computing a set of descriptive sample parameters and conducting Kolmogorov-Smirnov tests of normality of the empirical distributions of daily, weekly and monthly rates of return. All of the sample parameters are calculated in the usual ways and the Kolmogorov-Smirnov test statistic $Z_{K S}$ is calculated as $\sup |F(r)-N(r)|$ over all real values $-5<r<+5$ spaced at intervals of length 0.20 , where $r_{t}$ is the normalized rate of return (using sample mean and standard deviation), $F(r)$ is the empirical distribution function and $N(r)$ is the standard normal distribution function. The results are tabulated in Tables 2 and 3 . Daily calculations for all sample time periods are given in Table 2 . For weekly and monthly data, only the results for the two subperiods are reported in Table 3. In both tables, estimates that are significantly different from zero at $\alpha=5 \%$ level of significance are indicated in bold italics.

The results for daily data in Table 2 reveal some interesting points. On the average, the daily standard deviation is about ten times the daily mean rate of return. This coefficient of variation is much higher than those seen in developed markets and it is typical of many emerging markets around the world. Significance tests are conducted for estimates of skewness, kurtosis and the Kolmogorov-Smirnov 
Table 2. Sample statistics* of the ISE Index returns series (daily data)

\begin{tabular}{|c|c|c|c|c|c|c|c|c|}
\hline Period & Mean & Median & Max & Min & $\begin{array}{l}\text { Standard } \\
\text { deviation }\end{array}$ & Skewness & Kurtosis & $\begin{array}{l}Z_{K S} \\
\text { statistic }\end{array}$ \\
\hline \multicolumn{9}{|c|}{ Panel A: Subperiods } \\
\hline $88-99$ & 0.003 & 0.002 & 0.156 & -0.223 & 0.030 & -0.197 & 2.659 & 2.119 \\
\hline $88-94$ & 0.002 & 0.001 & 0.103 & -0.126 & 0.030 & -0.032 & 1.207 & 1.786 \\
\hline $95-99$ & 0.003 & 0.003 & 0.156 & -0.223 & 0.031 & -0.417 & 4.561 & 1.551 \\
\hline \multicolumn{9}{|c|}{ Panel B: Single years } \\
\hline 1988 & -0.002 & -0.004 & 0.080 & -0.088 & 0.024 & 0.131 & 2.109 & 1.144 \\
\hline 1989 & 0.007 & 0.005 & 0.084 & -0.078 & 0.029 & -0.097 & 0.746 & 0.910 \\
\hline 1990 & 0.002 & 0.000 & 0.103 & -0.126 & 0.035 & -0.272 & 0.788 & 0.749 \\
\hline 1991 & 0.001 & -0.002 & 0.098 & -0.107 & 0.034 & 0.408 & 0.918 & 1.079 \\
\hline 1992 & 0.000 & 0.000 & 0.088 & -0.101 & 0.022 & -0.061 & 2.579 & 0.752 \\
\hline 1993 & 0.007 & 0.007 & 0.100 & -0.110 & 0.026 & -0.082 & 1.407 & 0.463 \\
\hline 1994 & 0.001 & 0.003 & 0.085 & -0.111 & 0.036 & -0.201 & 0.245 & 0.907 \\
\hline 1995 & 0.002 & 0.004 & 0.082 & -0.095 & 0.025 & -0.577 & 1.406 & 0.671 \\
\hline 1996 & 0.004 & 0.002 & 0.095 & -0.048 & 0.020 & 0.616 & 1.581 & 0.669 \\
\hline 1997 & 0.005 & 0.006 & 0.123 & -0.118 & 0.030 & -0.263 & 3.024 & 1.068 \\
\hline 1998 & -0.001 & 0.000 & 0.156 & -0.223 & 0.041 & -0.659 & 4.293 & 1.165 \\
\hline 1999 & 0.008 & 0.004 & 0.119 & -0.109 & 0.033 & 0.112 & 1.244 & 0.759 \\
\hline \multicolumn{9}{|c|}{ Panel C: Updated periods } \\
\hline $88-99$ & 0.003 & 0.002 & 0.156 & -0.223 & 0.030 & -0.197 & 2.659 & 2.119 \\
\hline 89-99 & 0.003 & 0.002 & 0.156 & -0.223 & 0.031 & -0.228 & 2.639 & 1.997 \\
\hline $90-99$ & 0.003 & 0.002 & 0.156 & -0.223 & 0.032 & -0.234 & 2.778 & 1.808 \\
\hline $91-99$ & 0.003 & 0.002 & 0.156 & -0.223 & 0.031 & -0.224 & 3.099 & 1.687 \\
\hline $92-99$ & 0.003 & 0.003 & 0.156 & -0.223 & 0.031 & -0.335 & 3.534 & 1.486 \\
\hline 93-99 & 0.003 & 0.003 & 0.156 & -0.223 & 0.032 & -0.368 & 3.408 & 1.490 \\
\hline $94-99$ & 0.003 & 0.003 & 0.156 & -0.223 & 0.032 & -0.376 & 3.451 & 1.571 \\
\hline $95-99$ & 0.003 & 0.003 & 0.156 & -0.223 & 0.031 & -0.417 & 4.561 & 1.551 \\
\hline $96-99$ & 0.004 & 0.003 & 0.156 & -0.223 & 0.033 & -0.409 & 4.704 & 1.414 \\
\hline $97-99$ & 0.004 & 0.003 & 0.156 & -0.223 & 0.036 & -0.457 & 3.971 & 1.402 \\
\hline $98-99$ & 0.003 & 0.002 & 0.156 & -0.223 & 0.038 & -0.478 & 3.811 & 1.174 \\
\hline
\end{tabular}

* Those statistics that are significant at $\alpha=5 \%$ level are indicated in bold italics.

goodness-of-fit measures. For a sample size of $T$, approximate standard deviations for skewness and kurtosis estimates are $\sqrt{6 / T}$ and $\sqrt{24 / T}$, respectively, when the underlying process is at least asymptotically normal. At $5 \%$ probability level, the significance value of the Kolmogorov-Smirnov statistic is 0.895 (Law and Kelton, 1982). It is seen that most of the empirical distributions are leptokurtic and often skewed to the left. Kurtosis is more evident than skewness. (The year 1994 is an exception, when the lowest positive rate of return in a 12-year period was seen. It was not a typically 'overheated' year.) In daily data, Kolmogorov-Smirnov tests also reveal significant departures from normality, especially in longer time periods. A closer examination of the Kolmogorov-Smirnov results reveals two interesting points. First, when the results in Panel B for single years are compared 
to those in Panels A and C, it is seen that, as the length of the time period increases, the test statistic assumes higher values. This may be a possible indication of nonstationary behaviour. Second, when Panel C is examined, as time moves from 1988 to 1999 , the test statistic's value decreases almost monotonically. This may indicate a trend towards normality, or towards 'less non-normality.'

The findings from weekly and monthly data in Table 3 are markedly different from those with daily data. Skewness almost disappears in these data. This holds for both the subperiods reported in the table and also for single years (not reported). Leptokurtosis is still significant, though apparently at lower levels than daily samples. The Kolmogorov-Smirnov tests cannot reject the normality hypothesis in any of the monthly samples. There appears to be some weak departure from normality in weekly samples, however, the rejections are not as strong as in cases of daily samples. Since weekly and monthly returns are sums of daily returns, this finding may be interpreted as a manifestation of a central limit theorem for random variables with finite second moments. The persistence of leptokurtosis and the failure to reject normality at the same time may only be explained by a phenomenon that causes heavy tails but no excess peakedness in the centre of empirical densities. This may be either non-linear dependence or non-stationarity in the underlying stochastic process.

The above evidence suggests that the ISE return distributions may be moving towards a more Gaussian appearance as the market matures and also as the return interval becomes longer. However, there are significant departures from normality and suspicion of non-stationarity. Therefore, before looking in more detail into the time series implications of a white noise process, it may be useful to apply another non-parametric (albeit less powerful than most linear time series tests) and robust test of independence. For this purpose, the usual runs tests are applied on all samples and the results from daily and weekly samples are reported in Table 4. The test statistic is asymptotically a standard normal variate.

As seen in the table, none of the test statistics (possibly, with the exception of the 88-99 period for daily data) is significantly different from zero (at $5 \%$ level). The runs test cannot detect any statistical dependence in the series. Considering

Table 3. Sample statistics* of the ISE Index returns series (weekly and monthly data)

\begin{tabular}{lcccccccc}
\hline Period & Mean & Median & Max & Min & $\begin{array}{l}\text { Standard } \\
\text { deviation }\end{array}$ & Skewness & Kurtosis & $\begin{array}{l}Z_{K S} \\
\text { statistic }\end{array}$ \\
\hline \multicolumn{2}{l}{ Panel A: Weekly data } \\
$88-99$ & 0.013 & 0.011 & 0.330 & -0.340 & 0.077 & -0.124 & $\mathbf{1 . 6 7 8}$ & $\mathbf{1 . 0 3 8}$ \\
$88-94$ & 0.011 & 0.009 & 0.330 & -0.340 & 0.081 & -0.064 & $\mathbf{1 . 8 7 1}$ & 0.834 \\
$95-99$ & 0.016 & 0.013 & 0.230 & -0.246 & 0.072 & -0.210 & $\mathbf{1 . 1 2 8}$ & $\mathbf{1 . 0 2 2}$ \\
Panel B: Monthly data & & & & & & \\
$88-99$ & 0.053 & 0.043 & 0.587 & -0.495 & 0.170 & 0.335 & $\mathbf{1 . 0 2 9}$ & 0.621 \\
$88-94$ & 0.071 & 0.065 & 0.587 & -0.495 & 0.161 & 0.092 & $\mathbf{2 . 1 5 6}$ & 0.733 \\
$95-99$ & 0.067 & 0.055 & 0.585 & -0.493 & 0.167 & 0.217 & $\mathbf{2 . 7 2 1}$ & 0.616 \\
\hline
\end{tabular}

* Those statistics that are significant at $\alpha=5 \%$ level are indicated in bold italics. 
Table 4. Runs test statistics* on the ISE Index returns series (daily and weekly data

\begin{tabular}{llllll}
\hline Period & $\begin{array}{l}\text { Daily } \\
\text { returns }\end{array}$ & $\begin{array}{l}\text { Weekly } \\
\text { returns }\end{array}$ & Period & $\begin{array}{l}\text { Daily } \\
\text { returns }\end{array}$ & $\begin{array}{l}\text { Weekly } \\
\text { returns }\end{array}$ \\
\hline 1988 & 0.75 & 0.24 & $88-99$ & 2.12 & 0.63 \\
1989 & 1.37 & 0.34 & $89-99$ & 1.88 & 0.42 \\
1990 & 0.74 & 0.23 & $90-99$ & 1.49 & 0.24 \\
1991 & 0.20 & 0.03 & $91-99$ & 1.33 & 0.37 \\
1992 & 1.03 & 0.33 & $92-99$ & 1.43 & 0.31 \\
1993 & 0.81 & 0.12 & $93-99$ & 1.11 & 0.18 \\
1994 & 0.41 & 0.36 & $94-99$ & 0.86 & 0.20 \\
1995 & 0.46 & 0.37 & $95-99$ & 0.75 & 0.05 \\
1996 & 0.03 & 0.15 & $96-99$ & 0.63 & 0.16 \\
1997 & 0.46 & 0.16 & $97-99$ & 0.75 & 0.14 \\
1998 & 0.38 & 0.77 & $98-99$ & 0.60 & 0.36 \\
1999 & 0.43 & 0.15 & & & \\
\hline
\end{tabular}

* Those statistics that are significant at $\alpha=5 \%$ level are indicated in bold italics.

the low power of the test, this statement may be considered conclusive. However, for the purposes of this study, the more important finding is the decrease in the values of the runs statistic through time for daily data (from 1988 to 1999) and that the values for weekly data are almost uniformly smaller than those for daily data. These are consistent with the previous results of the Kolmogorov-Smirnov tests for asymptotic normality.

As has become customary in financial work, tests of stationarity are conducted by testing for the presence of a unit root. The test procedures are based on the augmented version of the standard Dickey-Fuller (1979) test. This test is based on ordinary least squares (OLS) estimate of the following autoregressive model:

$$
R_{t}=b_{0}+b_{1} t+(\rho-1) \ln \left(P_{t-1}\right)+\sum_{j=1}^{k} a_{j} R_{t-j}+\varepsilon_{t}
$$

In this equation, $R_{t}$ is the change in index value in period $t, b_{0}$ is an intercept, $b_{1} t$ is a linear time trend, $\varepsilon_{t}$ is an error term, and $k$ is the large enough number of lagged first-differenced terms so that $\varepsilon_{t}$ is approximately white noise.

The purpose in using the lagged changes in the dependent variable is to capture the effect of autocorrelated omitted variables. With the additional lagged terms it may be possible to estimate a model with asymptotically white noise error terms. The size and power properties of the ADF test are sensitive to the number of lagged terms used in the model (Schwert, 1989; Agiakoglou and Newbold, 1992). Several guidelines have been suggested in the literature for the appropriate choice of $k$. Ng and Perron (1995) examine these guidelines in detail and suggest that Hall's (1994) sequential 'general to specific' rule should be preferred to others. Using this rule, one starts with a large value of $k$, tests the significance of the last coefficient and reduces $k$ iteratively until a significant statistic is obtained. The output 
of the ADF test consists of the $t$-statistic on the estimate of the $(\rho-1)$ coefficient of the lagged test variable.

After several experimentations, the number of lagged terms to be used in the regression equation is chosen to be five for daily data. For weekly and monthly data, using one lagged term seems to provide sufficient fit. To account for the autocorrelation in the error terms due to omitted variables, Phillips (1987) and Phillips and Perron (1988) suggest a non-parametric correction to the standard statistics after estimation as an alternative to ADF test. Asymptotically, the statistics are corrected by the appropriate amount, so the same limiting distributions that apply to ADF test apply to Phillips-Perron (PP) test, but the estimation of additional parameters in the regression model is not required. Also, the test is argued to be robust under a variety of conditions, such as heteroscedastic or autocorrelated error terms. The Phillips-Perron test is applied to the following linear model:

$$
R_{t}=b_{0}+(\rho-1) \ln \left(P_{t-1}\right)+\varepsilon_{t}
$$

The null hypothesis is that $\rho=1$, showing a unit root and implying a time series with trend-stationary and difference-stationary increments (logarithms of prices). Unlike the ADF test, there are no lagged difference terms. Instead, the equation is estimated by ordinary least squares and then the $t$-statistic of the coefficient estimate is corrected for serial correlation in $\varepsilon_{t}$. The Newey and West (1987) procedure is used to obtain the variance estimates. The results are reported in Table 5 . In general, the hypothesis of a unit root cannot be accepted by either test in all of the daily samples and most of the weekly samples. These indicate a nonstationary time series for the ISE returns. Indeed, the coefficient $\rho$ is greater than one in almost all of the cases, showing an 'explosive' random process. However, in monthly samples covering single years, neither test can reject the presence of a unit root. Hence, for periods not longer than about one year, monthly returns on the ISE Index seem to follow a discrete random walk with a drift. Not surprisingly, non-stationarity becomes more visible in longer time periods. The most important finding is the decrease in the values of both test statistics through time and also as daily returns are summed to get weekly and monthly returns. As a first-step interpretation, the ISE seems to have evolved towards a less non-stationary price process from 1988 to 1999.

Clearly, unless the residuals are also stationary, a unit root can only be a necessary but not a sufficient condition for a random walk with stationary increments. In other words, 'unit root processes' may have predictable components, but a random walk of the white noise type for stock prices means that returns must be uncorrelated. That is, unit root tests may not reveal much about the relative efficiency of the market. Therefore, a closer examination of sample autocorrelations in the return series is called for and, as a first step, this is done by calculating the portmanteau $Q(L)$ statistic of Ljung and Box (1978) for various lags $L$ :

$$
Q(L)=T(T+2) \sum_{i=1}^{L}(T-i)^{-1} \hat{\rho}_{i}^{2}
$$


Table 5. Unit root tests of the ISE Index log-levels ( $t$-statistics)*

\begin{tabular}{|c|c|c|c|c|c|c|}
\hline \multirow[b]{2}{*}{ Period } & \multicolumn{2}{|c|}{ Daily series } & \multicolumn{2}{|c|}{ Weekly series } & \multicolumn{2}{|c|}{ Monthly series } \\
\hline & ADF test & PP test & ADF test & PP test & ADF test & PP test \\
\hline \multicolumn{7}{|c|}{ Panel A: Sub-periods } \\
\hline 1988-99 & -21.05 & -53.77 & -16.07 & -23.71 & -7.68 & -11.17 \\
\hline 1988-94 & -12.14 & -39.99 & -10.11 & -17.30 & -4.41 & -6.77 \\
\hline 1995-99 & -12.98 & -34.76 & -11.28 & -16.34 & -5.57 & -7.98 \\
\hline \multicolumn{7}{|c|}{ Panel B: Single years } \\
\hline 1988 & -6.19 & -15.18 & -7.15 & -7.44 & -2.25 & -1.67 \\
\hline 1989 & -5.26 & -13.91 & -4.80 & -5.98 & -2.09 & -3.17 \\
\hline 1990 & -6.13 & -15.28 & -5.14 & -6.75 & -1.03 & -1.68 \\
\hline 1991 & -6.06 & -16.37 & -5.12 & -7.44 & -2.18 & -3.16 \\
\hline 1992 & -6.66 & -16.92 & -5.19 & -7.25 & -2.09 & -3.16 \\
\hline 1993 & -5.64 & -16.82 & -4.59 & -6.22 & -2.87 & -3.41 \\
\hline 1994 & -6.79 & -16.74 & -3.31 & -6.81 & -1.87 & -3.34 \\
\hline 1995 & -7.52 & -16.50 & -4.65 & -7.18 & -3.48 & -3.49 \\
\hline 1996 & -6.66 & -16.93 & -7.98 & -8.16 & -2.30 & -3.59 \\
\hline 1997 & -5.60 & -14.67 & -4.72 & -7.96 & -2.02 & -1.62 \\
\hline 1998 & -7.06 & -15.17 & -5.27 & -7.21 & -2.33 & -4.64 \\
\hline 1999 & -4.56 & -15.53 & -4.38 & -4.55 & -0.05 & -1.83 \\
\hline \multicolumn{7}{|c|}{ Panel C: Updated periods } \\
\hline 1988-99 & -21.05 & -53.77 & -16.07 & -23.71 & -7.68 & -11.17 \\
\hline 1989-99 & -20.29 & -51.47 & -15.43 & -22.68 & -7.37 & -10.80 \\
\hline 1990-99 & -19.70 & -48.87 & -14.80 & -21.68 & -7.20 & -10.38 \\
\hline 1991-99 & -16.90 & -46.13 & -14.31 & -20.86 & -7.49 & -10.55 \\
\hline 1992-99 & -16.24 & -43.71 & -13.59 & -19.77 & -6.96 & -9.85 \\
\hline 1993-99 & -15.27 & -40.93 & -12.70 & -18.49 & -6.54 & -9.28 \\
\hline 1994-99 & -14.22 & -37.80 & -11.84 & -17.35 & -6.14 & -8.78 \\
\hline 1995-99 & -12.98 & -34.76 & -11.28 & -16.34 & -5.57 & -7.98 \\
\hline 1996-99 & -11.47 & -30.93 & -10.03 & -14.41 & -5.04 & -7.26 \\
\hline 1997-99 & -9.73 & -26.95 & -8.56 & -11.80 & -4.22 & -6.15 \\
\hline 1998-99 & -7.70 & -22.33 & -7.04 & -9.08 & -3.63 & -5.54 \\
\hline
\end{tabular}

* Those statistics that are significant at $\alpha=5 \%$ level are indicated in bold italics.

The test statistic $Q(L)$ is asymptotically chi-squared distributed with $L$ degrees of freedom and simulation studies have shown that $L \cong \ln (T)$ provides better test power. Some of the representative findings are reported in Table 6 .

The results show that there is significant autocorrelation in most daily series, in some weekly series and in few monthly series. In other words, sample autocorrelation seems to decrease as the returns are summed towards monthly intervals. More importantly, as the estimation period moves from the earlier years towards the later years, both the levels of autocorrelation and the levels of the test statistics decrease markedly. These are consistent with all of the previous findings.

If prices follow a white noise process with uncorrelated increments, the variance of the continuous-time rate of return over a given interval of time will be 
Table 6. Ljung-Box $[Q(L)]^{*}$ autocorrelation tests of the ISE Index return series

\begin{tabular}{|c|c|c|c|c|c|c|c|c|}
\hline \multirow[b]{2}{*}{ Period } & \multicolumn{3}{|c|}{ Daily series } & \multicolumn{3}{|c|}{ Weekly series } & \multicolumn{2}{|c|}{ Monthly series } \\
\hline & $\overline{Q(5)}$ & $\mathrm{Q}(10)$ & $\mathrm{Q}(30)$ & $\overline{Q(2)}$ & $\mathrm{Q}(4)$ & $Q(16)$ & $\overline{\mathrm{Q}(2)}$ & $\mathrm{Q}(8)$ \\
\hline \multicolumn{9}{|c|}{ Panel A: Sub-periods } \\
\hline $88-99$ & 77.84 & 87.52 & 102.40 & 8.28 & 9.72 & 25.87 & 18.58 & 10.39 \\
\hline $88-94$ & 121.38 & 130.56 & 150.47 & 46.23 & 56.84 & 23.42 & 0.79 & 85.40 \\
\hline $95-99$ & 8.84 & 13.04 & 37.57 & 3.48 & 5.02 & 20.45 & 1.02 & 12.88 \\
\hline \multicolumn{9}{|c|}{ Panel B: Single years } \\
\hline 1988 & 16.55 & 20.98 & 50.75 & 0.25 & 0.33 & 22.81 & 4.10 & 19.02 \\
\hline 1989 & 37.46 & 44.23 & 74.44 & 11.43 & 11.46 & 57.62 & 4.94 & 12.22 \\
\hline 1990 & 28.54 & 34.47 & 55.21 & 1.57 & 2.35 & 10.48 & 0.05 & 1.75 \\
\hline 1991 & 5.75 & 9.61 & 20.15 & 1.32 & 1.33 & 11.01 & 1.43 & 8.12 \\
\hline 1992 & 13.63 & 18.21 & 42.83 & 3.60 & 8.51 & 30.87 & 3.09 & 11.90 \\
\hline 1993 & 5.80 & 10.06 & 24.72 & 0.92 & 6.80 & 26.29 & 11.15 & 18.89 \\
\hline 1994 & 34.41 & 35.67 & 68.12 & 0.48 & 6.21 & 20.39 & 0.84 & 8.67 \\
\hline 1995 & 3.53 & 10.41 & 26.79 & 5.26 & 5.79 & 16.38 & 0.75 & 5.38 \\
\hline 1996 & 3.54 & 7.51 & 33.16 & 0.51 & 2.48 & 9.44 & 0.77 & 7.09 \\
\hline 1997 & 4.06 & 10.64 & 33.88 & 0.37 & 1.28 & 7.85 & 0.73 & 3.99 \\
\hline 1998 & 10.78 & 15.14 & 29.49 & 0.54 & 1.75 & 14.66 & 0.70 & 3.45 \\
\hline 1999 & 2.56 & 5.97 & 17.69 & 6.44 & 7.00 & 16.03 & 0.13 & 6.52 \\
\hline \multicolumn{9}{|c|}{ Panel C: Updated periods } \\
\hline $88-99$ & 77.84 & 87.52 & 102.40 & 8.28 & 9.73 & 25.87 & 1.85 & 10.39 \\
\hline 89-99 & 66.11 & 75.19 & 90.27 & 65.42 & 82.67 & 26.54 & 1.88 & 10.67 \\
\hline $90-99$ & 46.55 & 56.98 & 72.68 & 30.64 & 53.07 & 20.93 & 0.62 & 7.72 \\
\hline $91-99$ & 29.15 & 34.63 & 50.88 & 43.01 & 85.49 & 32.95 & 0.55 & 11.22 \\
\hline $92-99$ & 27.22 & 32.74 & 48.11 & 31.33 & 82.77 & 33.22 & 0.43 & 11.45 \\
\hline 93-99 & 23.59 & 27.67 & 43.29 & 16.88 & 70.68 & 31.95 & 0.63 & 11.51 \\
\hline $94-99$ & 21.29 & 24.27 & 42.90 & 0.71 & 5.77 & 25.44 & 1.40 & 11.81 \\
\hline 95-99 & 8.85 & 13.04 & 37.57 & 3.48 & 5.02 & 20.45 & 1.02 & 12.88 \\
\hline 96-99 & 7.92 & 10.83 & 31.29 & 28.89 & 55.64 & 17.56 & 0.56 & 6.79 \\
\hline $97-99$ & 5.77 & 8.76 & 24.56 & 25.25 & 53.49 & 16.51 & 0.41 & 3.53 \\
\hline 98-99 & 5.72 & 8.26 & 29.64 & 3.56 & 5.46 & 19.52 & 0.73 & 5.66 \\
\hline
\end{tabular}

* $Q(L)$ statistics that are significant at $\alpha=5 \%$ level are indicated in bold italics.

proportional to the length of the time period. Given a series of $N K+1$ equally spaced uncorrelated prices $P_{0}, P_{1}, \ldots, P_{N K}$, then

$$
\operatorname{Var}\left(\ln \left(\frac{P_{N K}}{P_{0}}\right)\right)=\operatorname{Var}\left(\sum_{t=1}^{N K} \ln \left(P_{t} / P_{t-1}\right)\right)=(N K) \sigma^{2}
$$

where $\sigma^{2}$ is the variance of the rate of return over one unit period of time. (Note the change in notation as $T=N K$.) This unit variance may be constant if variances are not changing over time or equal to the average of the $N K$ unit variances if there is heteroscedasticity. Clearly, this argument will not be valid if the logarithms of prices are serially correlated. Based on this very clear idea, Lo and MacKinlay 
(1988) derive the properties and suggest the use of the variance-ratio test as a powerful means of testing for white noise in prices. Considering all the desirable properties of this approach and the ease of interpreting its results, the varianceratio tests are presented here as one of the main methodologies of this study.

Following the formulation in Lo and MacKinlay (1988), the sample variance of the rate of return per unit of time, $\sigma_{1}^{2}$, and the sample variance of the rate of return over $K$ units of time, $\sigma_{K}^{2}$, are calculated as

$$
\begin{aligned}
\sigma_{K}^{2} & =\frac{1}{M} \sum_{t=k}^{N K}\left(\ln \left(\frac{P_{t}}{P_{t-K}}\right)-K \mu\right)^{2} \\
\sigma_{1}^{2} & =\frac{1}{N K-1} \sum_{t=1}^{N K}\left(\ln \left(\frac{P_{t}}{P_{t-1}}\right)-\mu\right)^{2}
\end{aligned}
$$

where $M=K(N K-K+1)(1-K / N K)$ is a 'sample size' adjusted for bias stemming from overlapping periods in the variance calculations. The variance ratio test statistic is then calculated as

$$
Z(K)=\frac{\left(\sigma_{K}^{2} / \sigma_{1}^{2}\right)-1}{\sqrt{\theta(K)}}
$$

where $\theta(K)$ is the asymptotic variance of the variance ratio $\left(\sigma_{K}^{2} / \sigma_{1}^{2}\right)$ and it has versions for both homoscedastic and also heteroscedastic return series (see Lo and MacKinlay, 1999 for details). The test statistic, denoted hereon as $Z(K)$ for homoscedastic returns and $Z^{*}(K)$ for heteroscedastic returns, is asymptotically a standard normal variate. The simulation studies by Lo and MacKinlay (1989) demonstrate the efficiency and asymptotic power of this test. Furthermore, in finite samples, the variance ratio test seems to be more reliable than the traditional tests of autocorrelation such as the aforementioned unit root and Ljung-Box tests.

The test is conducted for several $K$ values for daily, weekly and monthly data. The results for daily and weekly data for $K=2,4$, and 8 are reported in Table 7 and Table 8, respectively. The findings for other values of $K$ are not separately reported as they are very similar to those reported. The first point to notice is that $Z^{*}(K)$ values are smaller than $Z(K)$ values in all series, showing that correcting for heteroscedasticity reduces the size of the variance ratio statistics.

An inspection of Table 7 for daily data reveals two important findings. First, as the value of $K$ increases, the variance ratios become typically higher but, at the same time, the test statistics $Z(K)$ and $Z^{*}(K)$ become lower. This is possibly an indication of some long-term memory in prices but the information content of this memory becomes less and less significant as the time lag increases. In other words, whatever inefficiency may exist in the ISE prices, they seem to be eliminated in sufficiently long epochs of time. Secondly and more importantly, as the estimation period moves from 1988 to 1999, both the variance ratios and also the test statistics decrease in value, almost monotonically. When evaluated by itself only or in conjunction with the previous findings in the paper, this is a clear indication of a movement towards enhanced informational efficiency in the weak sense. 
Table 7. Variance ratio tests ${ }^{\dagger}$ on the ISE Index return series (daily data)

\begin{tabular}{|c|c|c|c|c|c|c|c|c|c|}
\hline \multirow[b]{2}{*}{ Period } & \multicolumn{3}{|l|}{$K=2$} & \multicolumn{3}{|l|}{$K=4$} & \multicolumn{3}{|l|}{$K=8$} \\
\hline & Ratio & $Z(K)$ & $Z^{*}(K)$ & Ratio & $Z(K)$ & $Z^{*}(K)$ & Ratio & $Z(K)$ & $Z^{*}(K)$ \\
\hline \multicolumn{10}{|c|}{ Panel A: Single years } \\
\hline 1988 & 1.222 & 3.539 & 2.525 & 1.278 & 2.365 & 1.721 & 1.445 & 2.391 & 1.855 \\
\hline 1989 & 1.353 & 5.635 & 4.016 & 1.426 & 3.634 & 2.587 & 1.606 & 3.271 & 2.389 \\
\hline 1990 & .336 & 5.279 & 4.245 & 1.462 & 3.882 & 3.164 & 1.399 & 2.118 & 1.741 \\
\hline 1991 & 126 & 1.985 & 1.524 & 1.108 & 0.903 & 0.728 & 1.217 & 1.155 & 0.960 \\
\hline 1992 & .140 & 2.216 & 2.185 & 1.124 & 1.051 & 0.963 & 1.349 & 1.870 & 1.711 \\
\hline 1993 & 086 & 1.342 & 1.314 & 1.108 & 0.908 & 0.895 & 1.197 & 1.042 & 1.034 \\
\hline 1994 & 379 & 6.031 & 4.516 & 1 & 4.9 & 3.631 & & & 2.859 \\
\hline 1995 & 037 & 0.586 & 0.494 & 19 & 1.008 & 7 & 9 & 0 & 0.699 \\
\hline 1996 & 01 & 1.589 & 1.331 & 1.220 & 1.847 & 4 & 99 & 1.590 & 1.394 \\
\hline 1997 & 17 & 1.854 & 1.162 & 1.170 & 1.441 & 0.924 & 38 & 0.737 & 0.521 \\
\hline 1998 & 933 & -1.043 & -0.927 & 0.992 & -0.066 & -0.059 & 926 & -0.391 & -0.339 \\
\hline 1999 & 093 & 1.422 & 1.058 & 1.159 & 1.297 & 1.021 & 1.243 & 1.258 & 1.076 \\
\hline \multicolumn{10}{|c|}{ Panel B: Updated periods } \\
\hline 88-99 & 1.158 & 8.639 & 6.330 & 1.245 & 7.157 & 5.329 & 1.329 & 6.072 & 4.608 \\
\hline 89-99 & 1.153 & 7.991 & 5.893 & 1.238 & 6.638 & 4.974 & 1.310 & 5.468 & 4.168 \\
\hline 90-99 & 1.135 & 6.693 & 4.951 & 1.214 & 5.700 & 4.290 & 1.263 & 4.420 & 3.383 \\
\hline $91-99$ & 1.109 & 5.121 & 3.751 & 1.182 & 4.586 & 3.420 & 1.250 & 3.993 & 3.036 \\
\hline 92-99 & 1.107 & 4.752 & 3.458 & 1.197 & 4.682 & 3.452 & 1.263 & 3.960 & 2.971 \\
\hline 93-99 & 1.103 & 4.299 & 3.147 & 1.199 & 4.424 & 3.286 & 1.251 & 3.521 & 2.663 \\
\hline 94-99 & 1.105 & 4.038 & 2.924 & 1.204 & 4.199 & 3.087 & 1.239 & 3.116 & 2.334 \\
\hline 95-99 & 1.032 & 1.114 & 0.805 & 1.110 & 2.065 & 1.527 & 1.125 & 1.477 & 1.120 \\
\hline 96-99 & 1.032 & 1.012 & 0.733 & 1.109 & 1.842 & 1.366 & 1.125 & 1.320 & 1.004 \\
\hline 97-99 & 1.026 & 0.711 & 0.544 & 1.114 & 1.443 & 1.131 & 1.104 & 0.947 & 0.761 \\
\hline 98-99 & 1.004 & 0.081 & 0.067 & 1.083 & 0.973 & 0.821 & 1.107 & 0.791 & 0.670 \\
\hline
\end{tabular}

${ }^{\dagger} Z(K)$ and $Z^{*}(K)$ statistics that are significant at $\alpha=5 \%$ level are indicated in bold italics.

The results in Table 8 for weekly data are markedly different from daily results in that most of the variance ratios are not significantly different from one. The observed dependence in daily series seems to disappear to a large extent when they are summed to get weekly series. (With the exception of the year 1999, which has to be interpreted as an aberration, the few significant test statistics again belong to the earlier years in ISE history.)

All of these findings are signs that the ISE has matured into a more efficient price mechanism during the decade studied here. Indeed, in monthly data, none of the test statistics are found to be significant at any level of probability.

Finally, to find out whether there are differences in the evolutionary behaviour of portfolios of different sized stocks, all of the test procedures are also applied on large, medium and small stock portfolios. No clear differences or patterns could be observed to shed any light of the often-cited size-effect on statistical behaviour. Therefore, these results are not reported. 
Table 8. Variance ratio tests ${ }^{\dagger}$ on the ISE Index return series (weekly data)

\begin{tabular}{|c|c|c|c|c|c|c|c|c|c|}
\hline \multirow[b]{2}{*}{ Period } & \multicolumn{3}{|l|}{$K=2$} & \multicolumn{3}{|l|}{$K=4$} & \multicolumn{3}{|l|}{$K=8$} \\
\hline & Ratio & $Z(K)$ & $Z^{*}(K)$ & Ratio & $Z(K)$ & $Z^{*}(K)$ & Ratio & $Z(K)$ & $Z^{*}(K)$ \\
\hline \multicolumn{10}{|c|}{ Panel A: Single years } \\
\hline 1988 & 1.169 & 1.220 & 1.279 & 1.010 & 0.039 & 0.041 & 0.318 & -1.662 & -1.750 \\
\hline 1989 & 1.484 & 3.425 & 3.150 & 1.908 & 3.433 & 3.093 & 1.802 & 1.917 & 1.745 \\
\hline 1990 & 0.895 & -0.743 & -0.638 & 0.858 & -0.537 & -0.474 & 0.692 & -0.737 & -0.692 \\
\hline 1991 & 1.125 & 0.884 & 0.820 & 1.398 & 1.506 & 1.405 & 1.609 & 1.455 & 1.450 \\
\hline 1992 & 1.292 & 2.047 & 1.619 & 1.507 & 1.898 & 1.654 & 0.936 & -0.152 & -0.143 \\
\hline 1993 & 1.141 & 0.975 & 1.315 & 1.226 & 0.838 & 0.917 & 0.703 & -0.695 & -0.686 \\
\hline 1994 & 1.018 & 0.128 & 0.092 & 0.744 & -0.977 & -0.689 & 0.573 & -1.032 & -0.757 \\
\hline 1995 & 0.915 & -0.598 & -0.517 & 1.231 & 0.865 & 0.747 & 1.775 & 1.835 & 1.632 \\
\hline 1996 & 1.118 & 0.831 & 1.023 & 1.179 & 0.677 & 0.810 & 1.591 & 1.412 & 1.593 \\
\hline 1997 & 0.983 & -0.118 & -0.160 & 1.015 & 0.058 & 0.058 & 0.846 & -0.373 & -0.358 \\
\hline 1998 & 0.999 & -0.004 & -0.005 & 1.162 & 0.602 & 0.603 & 1.700 & 1.640 & 1.654 \\
\hline 1999 & 1.408 & 2.766 & 2.629 & 1.407 & 1.474 & 1.467 & 1.657 & 1.506 & 1.560 \\
\hline \multicolumn{10}{|c|}{ Panel B: Updated periods } \\
\hline $88-99$ & 1.081 & 1.964 & 1.477 & 1.183 & 2.389 & 1.740 & 1.257 & 2.120 & 1.590 \\
\hline 89-99 & 1.069 & 1.603 & 1.201 & 1.166 & 2.064 & 1.492 & 1.237 & 1.865 & 1.388 \\
\hline 90-99 & 1.037 & 0.818 & 0.612 & 1.072 & 0.850 & 0.616 & 1.073 & 0.551 & 0.411 \\
\hline $91-99$ & 1.072 & 1.514 & 1.107 & 1.122 & 1.366 & 0.958 & 1.163 & 1.156 & 0.834 \\
\hline $92-99$ & 1.069 & 1.370 & 0.979 & 1.098 & 1.039 & 0.708 & 1.121 & 0.809 & 0.566 \\
\hline $93-99$ & 1.053 & 0.989 & 0.716 & 1.063 & 0.619 & 0.425 & 1.092 & 0.574 & 0.404 \\
\hline $94-99$ & 1.045 & 0.766 & 0.545 & 1.014 & 0.133 & 0.090 & 1.062 & 0.363 & 0.254 \\
\hline 95-99 & 1.061 & 0.963 & 0.972 & 1.196 & 1.647 & 1.505 & 1.438 & 2.321 & 2.107 \\
\hline 96-99 & 1.114 & 1.586 & 1.653 & 1.199 & 1.488 & 1.372 & 1.425 & 2.006 & 1.837 \\
\hline 97-99 & 1.122 & 1.469 & 1.610 & 1.212 & 1.366 & 1.322 & 1.384 & 1.562 & 1.506 \\
\hline $98-99$ & 1.204 & 2.074 & 2.103 & 1.370 & 1.915 & 1.821 & 1.788 & 2.584 & 2.490 \\
\hline
\end{tabular}

$\dagger Z(K)$ and $Z^{*}(K)$ statistics that are significant at $\alpha=5 \%$ level are indicated in bold italics.

\section{CONCLUSIONS}

The empirical findings in this study show that the asset prices in the Istanbul Stock Exchange have noticeably evolved towards a more informationally efficient process over time. As noted at the outset, it may be unrealistic to expect the empirical stochastic processes in speculative markets to be strict white noise processes. Informational efficiency is more properly defined as a price process, where the marginal benefit of prediction is not significantly greater than the cost of prediction of future returns. This is expected and, to a large extent, observed in fully developed markets like the NYSE. The ISE seems to be moving in that direction and to have accomplished considerable progress in little more than a decade of existence.

Finally, as an emerging market, the ISE has shown some differences from other emerging markets. Expected returns, as approximated by sample means, have not declined and no significant change in volatility is observed during the decade. 
The move towards normality in suitably summed returns also seems to be more pronounced than in other countries. As mentioned in the introduction section, all of these differences may stem from the unique characteristics of the particular market.

\section{REFERENCES}

Agiakoglou, C. and Newbold, P. (1992) Empirical evidence on Dickey-Fuller type tests, Journal of Time Series Analysis, 13, 471-83.

Aldous, D. (1989) Probability Approximations via the Poisson Clumping Heuristic. New York: Springer-Verlag.

Bekaert, G. and Harvey, C.R. (2002) Research in emerging markets finance: looking to the future, Emerging Markets Review, 3, 429-48.

Berlung, T. and Liljeblom, E. (1990) The impact of trading volume on stock return distributions: an empirical analysis, Finnish Economic Papers, 2, 108-23.

Black, F. (1986) Noise, Journal of Finance, 41, 529-43.

Bollerslev, T. (1986) Generalized autoregressive conditional heteroskedasticity, Journal of Econometrics, 31, 307-27.

Campbell, J.Y., Lo, A.W. and MacKinlay, A.C. (1997) The Econometrics of Financial Markets. New Jersey, Princeton: Princeton University Press.

Chan, L.K.C. and Lakanishok, J. (1992) Robust measurement of Beta risk, Journal of Financial and Quantitative Analysis, 27, 265-82.

Cowles, A. and Jones, H.E. (1937) Some a posteriori probabilities in stock market action, Econometrica, 5, 280-94.

Dickey, D. and Fuller, W. (1979) Distribution of the estimators for autoregressive time series with a unit root, Journal of the American Statistical Association, 74, 427-31.

Engle, R. (1982) Autoregressive conditional heteroscedasticity with estimates of the variance of United Kingdom inflation, Econometrica, 50, 987-1007.

Fama, E. (1965) The behaviour of stock market prices, Journal of Business, 38, 34-105.

Fama, E.F. (1970) Efficient capital markets: a review of theory and empirical work, Journal of Finance, 25, 383-417.

Fama, E.F. (1991) Efficient capital markets: II, Journal of Finance, 46, 1575-617.

Fama, E.F. and French, K.R. (1988) Permanent and temporary components of stock prices, Journal of Political Economy, 96, 246-73.

Grossman, S.J. and Stiglitz, E. (1980) On the impossibility of informationally efficient markets, American Economic Review, 71, 393-408.

Hall, A. (1994) Testing for a unit root in time series with pretest data-based model selection, Journal of Business and Economic Statistics, 12, 461-70.

Law, A.M. and Kelton, W.D. (1982) Simulation Modeling and Analysis. New York: McGraw-Hill.

LeRoy, S. (1973) Risk aversion and the martingale property of stock returns, International Economic Review, 14, 436-46.

Ljung, G. and Box, G. (1978) On a measure of lack of fit in time series model, Biometrika, 65, 297-303.

Lo, A.W. and MacKinlay, A.C. (1988) Stock market prices do not follow random walks: evidence from a simple specification test, Review of Financial Studies, 1, 41-66.

Lo, A.W. and MacKinlay, A.C. (1989) The size and power of the variance ratio test in finite samples: a Monte Carlo investigation, Journal of Econometrics, 40, 203-38.

Lo, A.W. and MacKinlay, A.C. (1999) A Non-random Walk down Wall Street. New Jersey, Princeton: Princeton University Press.

Lucas, R.E. (1978) Asset prices in an exchange economy, Econometrica, 46, 1429-45. 
Newey, W.K. and West, D.W. (1987) A simple positive semi-definite, heteoskedasticity and autocorrelation consistent covariance matrix, Econometrica, 55, 703-708.

$\mathrm{Ng}, \mathrm{S}$. and Perron, P. (1995) Unit root tests in ARMA models with data-dependent methods for the selection of the truncation lag, Journal of American Statistical Association, 90, 268-81.

Phillips, P.C.B. (1987) Time series regression with a unit root, Econometrica, 55, 277-301.

Phillips, P.C.B. and Perron, P. (1988) Testing for a unit root in time series regression, Biometrika, 75, 335-46.

Poterba, J.M. and Summers, L.H. (1988) Mean-reversion in stock prices: evidence and implications, Journal of Financial Economics, 22, 27-59.

Schwert, G.W. (1989) Tests for unit roots: a Monte Carlo investigation, Journal of Business and Economic Statistics, 7, 147-59. 